\title{
Older Adults Adoption, Use and Diffusion of E-Government Services in Saudi Arabia, Hail City: A Quantitative Study
}

\author{
Jyoti Choudrie \\ University of Hertfordshire, UK \\ j.choudrie@herts.ac.uk
}

\author{
Adel Alfalah \\ University of Hertfordshire, UK \\ aas131@,hotmail.com
}

\author{
Neil H. Spencer \\ University of Hertfordshire, UK \\ n.h.spencer@herts.ac.uk
}

\begin{abstract}
Online Government products and services should provide benefits to all citizens, but not all of them are attaining the gains. A group that is not obtaining the benefits is the older adults. Such differences have led to a phenomenon known as the digital divide, which is a research gap that researchers are attempting to eliminate. Using this as motivation, this study aims to identify, explain and understand the adoption and use of e-Government services within the older adults of a vicinity in Saudi Arabia. This study uses a quantitative approach that collated data using a survey questionnaire from Hail city households and led to 278 completed replies. Findings depicted that age-based, gender-based and education-based digital divides do exist in Saudi Arabia. The obtained findings provide implications for the existing literature on e-Government adoption, for practitioners and policy makers.
\end{abstract}

\section{Background to the Research Problem}

To obtain economic growth, governments around the globe are implementing a telecommunications infrastructure for the proliferation of Information and Communications Technologies (ICT) to occur [1]. However, these changes have led to certain groups of society accepting and using the new ICT, which has led to differences within societies and even within nations; thereby, leading to an uneven distribution of novel technologies and a digital divide [2].

A group of society within countries that is currently not accepting and using e-Government is the older adults [3]. According to the World Health Organization (WHO) [4], definitions of older adults differ among countries, with developed countries viewing older adults as individuals who receive pension aids. Comparatively, in developing countries, in Africa for example, the WHO suggests that the older adult concept should relate to people who are aged either 50 or 55 and above. For the purposes of this research, 'Older adults' are defined as 'an adult, generally 50 years of age or older, who continually spends time online and surfs the Web and are known as silver surfers ("silver" refers to the colour of their hair) [5].

When considering e-government, older adults and ICT research, it has been found that there is minimal literature on this topic. Further, when ascertaining whether these topics had been considered in Saudi Arabia, it was even less pronounced, which suggested the existence of a research gap. This disparity motivated the research team to form the aim: To identify, explain and understand the adoption and use of e-Government services within the older adults of a vicinity in Saudi Arabia. By fulfilling this aim, academia, practitioners and policymakers will benefit from a better understanding of e-government services and older adults in a vicinity of Saudi Arabia. The research will examine e-services provided to citizens by the Ministry of Interior (MOI) in Saudi Arabia. The MOI e-Portal is the central governmental e-platform that links together various governmental bodies, such as the civil affairs, passport and traffic departments in order to facilitate and provide e-government services to citizens (refer to figure 1). The MOI e-Portal was also selected because it is the main online gate for Saudi citizens to interact with the government, to request and to conduct the majority of the civil services.

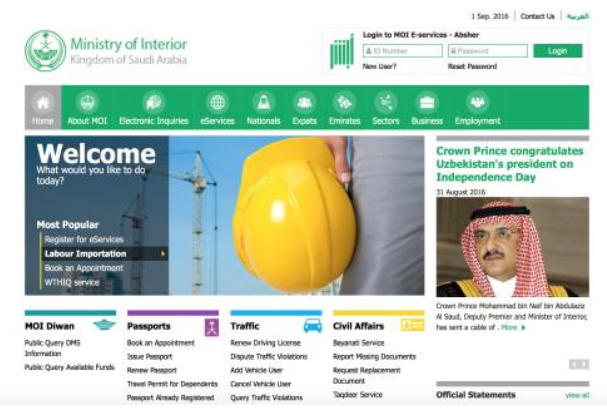

Figure 1: The main page of MOI e-portal 


\section{Literature Review}

When considering e-government development in Arab countries, limited studies are evident; hence knowledge of present e-Government development initiatives would be beneficial. Within the Arab countries and e-government research, the United Arab Emirates (UAE), Bahrain and Qatar are leaders in Arab e-government research as they offer their citizens advanced e-Government services. However, Yemen, Iraq, and Sudan lack e-government services, which is not a surprise given the political turmoil the governments face. Of other Arab countries, it was noticed that Saudi Arabia, Kuwait and Lebanon offer a wide variety of e-Government services [6].

\subsection{Challenges and Barriers to e- Government Services Adoption}

Academic research has identified various hurdling factors, which reduce the level of e-government diffusion and adoption in diverse countries. Some of these factors include, the availability and accessibility of ICT, which have caused the digital divide [7], [8], [9]; usability [10]; risk [11], and trust [12]. Within these factors, accessibility and computer literacy have largely contributed to the digital divide creation within countries and among citizens.

Further, given the online environmental resemblance between e-commerce and e-government, there is a rich source of knowledge that e-government studies can draw upon and benefit from [12]. A recent study conducted in the United States of America (USA) to investigate online shopping intentions within the younger $(<55)$ and older $(>55)$ adults in the context of a major data breach [13] found that for both the age categories, perceived online shopping risk is considerably influenced by the acuity of a hacking event. However, this perceived risk negatively influences the older adults' intentions of online shopping greater than the younger adults.

Similarly, in e-commerce research, [14] designed a trust-based consumer decision-making model that examined links between trust, purchase intentions and perceived risk. Results suggested that the purchase intention of consumers is affected by their trust of the Internet and risk perceptions.

\subsection{Digital Divide and ICT adoption of Older Adults}

In digital divide research, age has been identified as an important factor for its understanding within societies [15]. In some countries of the Middle East there is acceleration in the elderly population due to increased life expectancy and declined fertility rates. For example, in Saudi Arabia life expectancy is predicted to currently reach the age of 75 and will reach 80 years old by 2050 . Older adults are presently expected to form approximately $13 \%$ of the total population of the country. Additionally, within smaller Gulf countries such as, Bahrain, Kuwait and the United Arab Emirates (UAE), fertility rates have declined over the past 40 years; hence the countries also face an older adult population [16].

In addition to age, the older adults' adoption of ICT is also influenced by many other factors including, gender, ICT illiteracy, education level and degree of ICT necessity [3], [17].

\subsection{ICT, e-Gov and Older Adults in the Middle East}

Focusing on the commonly ignored aspect of eGovernment services implementation quality, [18] more so in developing countries, it is argued that the quality of services in government websites is a key element for the adoption (acceptance) of ICT within citizens. Research has explored many quality aspects of offered online services, such as the degree of information comprehension, ease of navigation, transparency, system availability, personalization, processing time, interactivity, credibility, security, and privacy. It was found that e-Government websites in Saudi Arabia need careful consideration with regards to service quality, which if addressed in terms of the citizens individuals requirements and needs being met, could lead to an increase in citizens' adoption numbers.

A study from Israel found limited adoption of ICT in the elderly, with many citizens expressing the view that their quality of life would not be considerably enhanced by ICT. However, it was found that perceived usefulness is a major factor for the elderly when adopting ICT [15]. In Oman, a study considering the use of ICT revealed that non-technical hurdles including, a lack of a marketing campaign and lesser knowledgeable users had negatively impacted the citizens' decision to adopt technology for eGovernment initiatives [19].

A research of Kuwait's e-government initiatives considered aspects impacting the adoption of eGovernment services [20]. These aspects included, social and cultural influences, perceived usefulness, ease of use, trust in the Internet and other factors related to gender, technical and awareness issues. Finally, a study concerning Saudi Arabia found that many factors influenced e-Government adoption including, information security, compatibility, 
complexity, availability and culture. It also emphasized some socio-demographic factors such as, age, gender, and education [21].

\section{Development of the Conceptual Model and Hypothesis}

Learning theories of change attitude attempt to clarify the mechanisms of how attitudes are being shaped by an individual [22], [23]. Many behavioural and pioneering research studies, such as the theory of reasoned action (TRA) have adopted learning theories such as, the principal theoretical model for their work [24]. Learning theories take into consideration three major aspects of attitude formation: social learning (equivalent to social influence in UTAUT \& subjective norms in TAM), classical conditioning, and operant conditioning [25]. In this study, classical conditioning has been excluded as it relates more to an individual's extroversion and sociability, and does not align with the aim of this study.

A trust model that has been applied in previous adoption studies is also considered by this research where trust refers to an individual's confidence such that an assurance made by individuals or groups in society are reliable [26], [27]. The Theory of reasoned Action (TRA) is utilized as a guiding framework for the trust model. TRA suggests that beliefs have impacts on intentions, which in turn have impacts on individual's actions [28]. The Trust model applied to this study is composed of four constructs: The disposition to trust, trust of the Internet, trust of the government, and perceived risk. An additional theory adopted by this study is the Diffusion of Innovation (DOI) theory of [29] that is intended to justify and explore user acceptance of new technologies (innovations) in which these technologies are considered to be novel. For readers' information, diffusion is 'the process by which an innovation is communicated through certain channels over time among the members of a social society' (ibid). DOI suggests that an innovation is influenced by five major constructs: Relative advantage, complexity, compatibility, trialability and observability. In this study, only relative advantage, complexity, and compatibility are included in the model whereas trialability and observability are excluded as they are considered of less relevance to adoption studies [30].

Furthermore, image, visibility and voluntariness are factors that assist in the understanding of the influential factors of an innovation adoption and use [31], which are taken from the extended model,
Perceived Characteristics of innovating (PCI). Of the three aforementioned additional factors, image is also included in this study as it serves the purpose of the current study. Having provided a theoretical background of this research study, the next section presents the constructs and hypothesis of this research.

\subsection{Constructs and Hypothesis}

Social influence (Primary Influence, PI) refers to the impact a reference group has on an individual's behaviour. The reference group includes family members, partners, friends and colleagues [32]. For this research, it is proposed that:

H1: Social influence will positively relate to older adults' intention to use MOI e-Portal.

Perceived cyber risk (PCR) relates to an individual's reluctance and/or hesitations to use an online system due to the likelihood of being a victim of cybercrimes [33]. For this research, it is proposed that: H2: Perceived cyber risk will negatively relate to older adults' intention towards using MOI e-Portal.

Perceived website assistance (PWA) is the perception that a website facilitates a user's activities and provides suitable support when needed [34]. For this research, it is proposed that: H3: Perceived website assistance will positively relate to older adults' intention toward using The MOI e-Portal.

Compatibility (COM) refers to 'the degree to which an innovation is seen to be compatible with existing values, beliefs, experiences and needs of adopters' [29]. Thus, it is proposed that: H4: Greater levels of perceived compatibility will positively relate to older adults' intention to use The MOI e-Portal.

Relative advantage (RA) is the perception that an individual develops, in which he or she can conduct a task more easily by adapting the new innovation [29]. For this research, it is proposed that: H5: Greater levels of relative advantage will positively relate to older adults' intention to use The MOI e-Portal.

Image (IM) refers to 'one's perceptions of an innovation as a status symbol' [31]. For this research, it is proposed that: H6: Greater levels of perceived image will positively relate to older adults' intention to use The MOI e-Portal.

Complexity (COMP) is 'the degree to which an innovation is seen by the potential adopter as being relatively difficult to use and understand' [29]. For this research, it is proposed that: H7: Greater levels of perceived complexity will negatively relate older adults' intention to use The MOI e-Portal.

Perceived risk (PR) is "the citizen's subjective expectation of suffering a loss in pursuit of a desired outcome" [35]. For this research, it is proposed that: H8: Perceived risk will negatively relate to older 
adults' intention to use The MOI e-Portal.

P.S. the items of this construct are broader and more general than the items of Perceived Cyber Risk (PCR). This construct is designed to obtain an idea of how older adults view online risks in general whereas PCR is more focused on specific online risks associated with utilizing the MOI e-Portal.

Trust of the Internet (TOI) refers to 'an individual's perceptions of the institutional environment, including the structures and regulations that make an environment feel safe' [36]. Furthermore, as this construct influences both the perceived risk and the intention to use e-Government services, it is proposed that:

H9: A Higher trust of the Internet (TOI) will reduce older adults' perceived risk of using The MOI ePortal. H10: Trust of the Internet (TOI) will positively relate to older adults' intention to use The MOI e-Portal.

Trust of the government (TOG) refers to 'one's perceptions regarding the integrity and ability of the agency providing the service [36]. Similar to TOI, trust of the government influences both the perceived risk and the intention to use e-Government services (MOI e-Services). Thus, it is proposed that:

H11: Higher trust of the government (TOG) will reduce older adults' perceived risk of using The MOI e-Portal. H12: Trust of the government (TOG) will positively relate to older adults' intention to use The MOI e-Portal.

Disposition to trust (DTT) is defined as whether an individual tends to have faith and trust in others, without any immediate external influential factor [36]. For this research, it is proposed that: H13: Disposition to trust will positively relate to older adults' trust of the Internet (TOI). H14: Disposition to trust will positively relate to older adults' trust of the government (TOG).

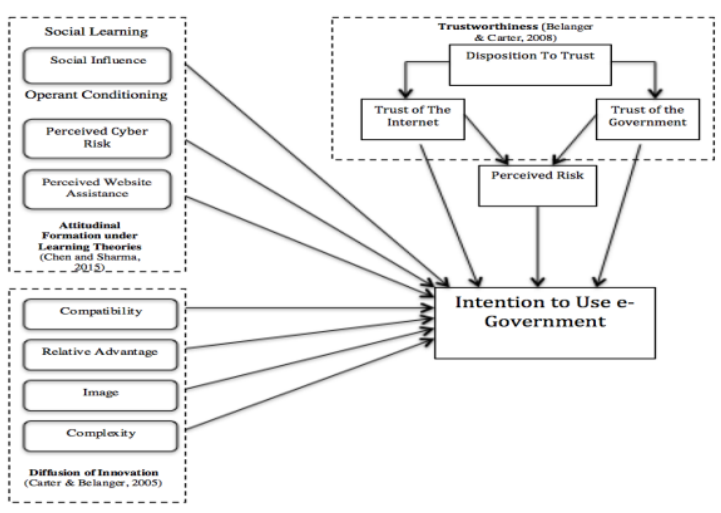

Figure 2: Research conceptual framework

\section{Research Approach and Sampling}

For this research, a quantitative approach was utilised that involved the use of survey questionnaires that were disseminated in both the hard and soft copies form. The questionnaire consisted of close ended questions that gauged the citizens' opinions using a 7 range Likert scale. Prior to distribution, content validity results were obtained to ensure phrasing, relevance, language clarity and understanding of the questions was evident. This was provided by 10 experts drawn from academia, citizens and practitioners.

The data collection period was between the periods of $23^{\text {th }}$ August and $26^{\text {th }}$ of October in 2015. To obtain the required sampling population for this pilot study, a combination of a non-random sampling method involving self-selection and snowball sampling were used. To ensure successful participants recruitment, a self-selection approach with already established contacts was initiated, which was followed by seeking contacts to recruit more participants from their personal and work contacts, which resulted in the pursuit of the snowball approach. The researcher visited households in Hail City and distributed 400 questionnaires to potential participants that led to 278 responses (both hard \& soft copies). Of these 257 were valid and complete. Using the reasoning that responses between 100 and 200 are considered to be sufficient for a pilot study intending to undertake a comprehensive item analysis [37], it was felt that 257 replies are suitable for this study. Due to the cultural aspects and to be respectful to older adults, the researcher made visits to the households of citizens with a female associate.

\subsection{Research Site Selection}

The research site for this study is Hail City that is located in the heart of the northern region of Saudi Arabia. It is also considered to be the capital of the north and links all the other northern cities of Saudi Arabia with the capital city (Riyadh), the holy city of Mecca, and the southern regions of the country. By the year 2016 (this year), the population of Hail city is expected to reach an estimated 700,000. As of 2007, about $13 \%$ of the total population constituted an older adults population $(\leq 50)$ [38]. These characteristics of Hail city suggested that it is an important city that is also a suitable context for this research. Further, the principal researcher has established contacts and access to the city that provided further reasons for its selection as the context.

\section{Data Analysis}




\subsection{Descriptive Data Analysis}

When this study began, it was known beforehand that the cultural and traditional norms of the Saudi society and the division between genders emphasize the role of the male. Therefore, it was expected that the male participants would outnumber the females'. In an attempt to reduce any possible nonresponse bias, gender-weighting procedures were applied using the data analysis software package SPSS version 2.0. Results showed that $187(72.6 \%)$ of the 257 respondents already adopted the Internet, while 69 $(26.8 \%)$ respondents did not adopt the Internet, and 1 $(0.5 \%)$ respondent planned to adopt the Internet. Table 1 below reveals that although the genderweighting technique was applied, results implied that there was larger Internet diffusion within the males compared to females. Further, age is an important influential element with regard to Internet adoption among older adults as outcomes show a clear decrease in the likelihood of Internet adoption as age increases. In terms of the level of education, results indicate that the higher the education level of an older adult, the more the likelihood of an individual to adopt the Internet. Finally, it can be clearly seen that there is a strong connection between the participants' health status and Internet adoption, where the better the health status of an individual, the greater the likelihood of Internet adoption and vice versa. In addition, it is worthwhile to note that the majority of the "poor" health status' participants were above 70 years old at $78.2 \%$. This also an indication of the significance of age as a leading factor when considering Internet adoption.

Table 1. Gender-weighted sociodemographic summary \& Internet adoption $(n=257)$

\begin{tabular}{|c|l|c|c|c|c|}
\hline \multicolumn{2}{|c|}{ Category } & $\begin{array}{c}\text { Intern } \\
\text { et } \\
\text { Adopt } \\
\text { ers }\end{array}$ & $\begin{array}{c}\text { Non- } \\
\text { Ado } \\
\text { pter } \\
\text { s }\end{array}$ & $\begin{array}{c}\text { Plans } \\
\text { to } \\
\text { adopt }\end{array}$ & Total \\
\cline { 3 - 6 } & $\%$ & $\%$ & $\%$ & $\%$ \\
\hline \multirow{4}{*}{ Gender } & Male & 80 & 18.9 & 1.1 & 50 \\
\cline { 2 - 6 } & Female & 65.3 & 34.7 & 0 & 50 \\
\cline { 2 - 6 } & Total & 72.6 & 26.8 & 0.5 & 100 \\
\hline \multirow{4}{*}{ Age } & $50-59$ & 97.2 & 0.9 & 1.9 & 29.2 \\
\cline { 2 - 6 } & $60-69$ & 88.5 & 11.5 & 0 & 39.7 \\
\cline { 2 - 6 } & $70-79$ & 38.7 & 61.3 & 0 & 22.2 \\
\cline { 2 - 6 } & $80-89$ & 8 & 92 & 0 & 6.7 \\
\cline { 2 - 6 } & Over 90 & 0 & 100 & 0 & 2.2 \\
\cline { 2 - 6 } & Total & 72.6 & 26.8 & 0.5 & 100 \\
\hline \multirow{2}{*}{$\begin{array}{c}\text { Educati } \\
\text { on }\end{array}$} & $\begin{array}{l}\text { Higher } \\
\text { Degree }\end{array}$ & 100 & 0 & 0 & 4.4 \\
\hline
\end{tabular}

\begin{tabular}{|c|l|c|c|c|c|}
\hline \multirow{1}{*}{} & $\begin{array}{l}\text { 1st } \\
\text { Degree }\end{array}$ & 93.9 & 2 & 4.1 & 13.2 \\
\cline { 2 - 5 } & $\begin{array}{l}\text { College } \\
\text { Dip. }\end{array}$ & 98.3 & 1.7 & 0 & 16.1 \\
\cline { 2 - 5 } & $\begin{array}{l}\text { Technic } \\
\text { al Cert. }\end{array}$ & 100 & 0 & 0 & 6.6 \\
\cline { 2 - 6 } $\begin{array}{l}\text { Second } \\
\text { ary } \\
\text { School }\end{array}$ & 89.5 & 10.5 & 0 & 18.4 \\
\cline { 2 - 6 } & $\begin{array}{l}\text { Primary } \\
\text { School }\end{array}$ & 79.4 & 20.6 & 0 & 18 \\
\cline { 2 - 6 } & $\begin{array}{l}\text { Read \& } \\
\text { Write }\end{array}$ & 17.6 & 82.4 & 0 & 14 \\
\cline { 2 - 6 } & $\begin{array}{l}\text { Illiterate } \\
\text { Health }\end{array}$ & 2.9 & 97.1 & 0 & 9.4 \\
\cline { 2 - 6 } Status & Total & 72.6 & 26.8 & 0.5 & 100 \\
\hline \multirow{5}{*}{$\begin{array}{l}\text { Excelle } \\
\text { nt }\end{array}$} & 96 & 1.3 & 2.7 & 20.3 \\
\cline { 2 - 6 } & Good & 84.5 & 15.5 & 0 & 49.2 \\
\cline { 2 - 6 } & Poor & 38 & 62 & 0 & 30.6 \\
\cline { 2 - 6 } & Total & 72.6 & 26.8 & 0.5 & 100 \\
\hline
\end{tabular}

\subsection{Constructs Reliability \& Validity}

Reliability measures consistency of the constructs [39]; therefore, constructs reliability must be determined. To accomplish reliability, Cronbach's Alpha, Composite Reliability and Average Variance Extracted (AVE) were determined. Sufficient values of Cronbach's Alpha, Composite Reliability and AVE are above or equal to $0.7,0.7$ and 0.5 respectively [40]. Analysis revealed that all the constructs met the reliability measurement criterion (Shown in Table 2). Further, to establish validity of the constructs, factor loadings were generated where the loads indicated the correlation between each item and its construct. All the factors demonstrated a strong load of 0.7 or above [40] except for the item IM4. Due to the pages count restriction of this paper, the factor loadings table is not included; however, results are available upon request from authors.

Table 2. AVE, composite reliability \& cronbach's alpha

\begin{tabular}{|l|l|l|l|}
\hline Construct & AVE & $\begin{array}{c}\text { Composite } \\
\text { Reliability }\end{array}$ & $\begin{array}{c}\text { Cronbach } \\
\text { 's Alpha }\end{array}$ \\
\hline COMP & 0.923 & 0.983 & 0.979 \\
\hline COM & 0.922 & 0.979 & 0.971 \\
\hline DTT & 0.809 & 0.944 & 0.920 \\
\hline IM & 0.699 & 0.851 & 0.749 \\
\hline PCR & 0.948 & 0.986 & 0.981 \\
\hline PI & 0.986 & 0.995 & 0.993 \\
\hline PR & 0.983 & 0.991 & 0.983 \\
\hline PWA & 0.850 & 0.984 & 0.982 \\
\hline RA & 0.908 & 0.980 & 0.974 \\
\hline TOG & 0.892 & 0.970 & 0.959 \\
\hline
\end{tabular}




\begin{tabular}{|l|l|l|l|}
\hline TOI & 0.950 & 0.983 & 0.974 \\
\hline UI & 0.969 & 0.992 & 0.989 \\
\hline
\end{tabular}

\subsection{Structural Model Analysis}

The model was analysed and tested using SmartPls software version 2.0. This software applies the analysing technique of Partial Least Squares based Structural Equation Modelling (PLS-SEM) that was considered to be suitable for this study due to: 1) PLS-SEM is effective when the research is exploratory and is attempting to identify or predict fundamental target constructs, which is the purpose of this study. We were exploring the association between age and e-government services. 2) PLS-SEM is also appropriate for relatively complex structural model that includes several constructs and several items, which is applicable to this study [41].

\subsection{Coefficient of Determination $\left(R^{2}\right)$}

The Coefficient of Determination $\left(\mathrm{R}^{2}\right)$ depicts the extent a dependent variable within a model can be understood and explained by the independent variables of the model. For the central dependent variable (intentions to use) $\mathrm{R}^{2}$ is 0.927 ; thereby, indicating that approximately $92 \%$ of the variability within the older adults' intentions to use the egovernment services (MOI e-Portal) can be explained by the model.

For the latent variable perceived risk, the $\mathrm{R}^{2}$ is 0.654 where $65 \%$ of the inconsistency in perceived risk can be explained by the unevenness in trust of the Internet and trust of the government. Additionally, $\mathrm{R}^{2}$ values of $0.75,0.50$, or 0.25 in the structural model are labelled as significant, moderate, or poor, respectively. Therefore, the $\mathrm{R}^{2}$ value of 0.927 can be interpreted as significant and the second $\mathrm{R}^{2}$ value of 0.654 is above the moderate range, which implies that both the values establish sufficient explanatory power [41].

\subsection{Path coefficients' significance}

A basic path analysis of the model was run on SPSS. The path analysis assists in determining the effect of the explanatory variables on the dependent variables. The values between the explanatory variables and the dependent variables are the path coefficients where indications of significance are offered. In addition, bootstrapping analysis was also used in SPSS. Bootstrapping offers more reliable assessments of the path coefficients' significance by using the available data as a distribution in order to compute sampling errors and produce t-values. Significance was based on the rules of thumb for structural model evaluation, "Critical t-values are 1.65 (significance level $=10$ percent), 1.96 (significance level $=5$ percent), and 2.58 (significance level $=1$ percent)" [42]. In terms of this research, 9 of the 14 hypotheses were supported by the outcomes of the model evaluation with some disparities amongst them (refer to figure 3). For example, the construct, Trust of the Internet (TOI) displayed a very strong relationship with the dependent key variable Intentions to Use (UI) (coefficient $=0.226$ ); thereby indicating that the older adults' intention to use the MOI e-Portal are hugely affected by their perception of the Internet and trust of it. Another example is the Compatibility construct (COM), which also revealed a strong relationship with UI (coefficient $=0.203$ ). This implies that the more compatible the MOI e-Portal is to older adults needs and requirements, the more their intentions are to use it. Comparatively, there are five hypotheses that were not supported by the analysis, which are Primary Influence (PI) (0.042); Perceived Cyber Risk (PCR) (0.056); Relative Advantage (RA) (0.148), Image (IM) (0.002), and Trust of The Government (TOG) (0.022). An overall model of the evaluation results is depicted in figure 2 below. Having illustrated this study's structural model, the following section provides a discussion of the findings and analysis.

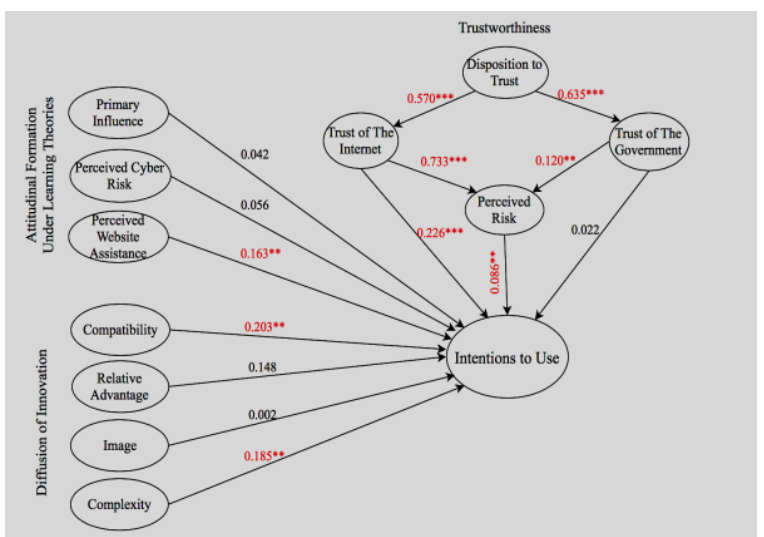

Figure 3: Structural model evaluation

\section{Discussion and Implications}

Having recognised the significance of this study's results and identifying the relevant and lesser relevant hypothesis, this section now attempts to position the findings within the context of the previously stated existing literature.

\subsection{The Older Adults \& Digital Divide}

Although the use of ICT in the older adults' population is growing, it has not increased to a level 
such that disparities in the diverse age groups diminish; hence an age-based digital divide exists [17], [7]. The importance of the age factor with respect to ICT and Internet adoption was also confirmed by this research. That is, there is a clear decrease in the likelihood of Internet adoption as age increases. The level of Internet adoption for the age groups of 50-59, 60-69, 70-79 and 80-89 was 97.2\%, $88.5 \%, 38.7 \%$ and $8 \%$ respectively (table 1 ).

Further, research on the elderly found that when adopting ICT, perceived usefulness is an important factor of consideration [15]. However, the findings of this study did not indicate a strong correlation between relative advantage-which is comparable to perceived usefulness [42] as cited in [12] - and older adults' intentions to use e-Gov services. Additionally, ICT illiteracy is a key deterrent of adoption within the older adults [17]. The findings of this research also found that a strong negative impact of ICT illiteracy in Internet adoption. $77.7 \%$ of the non-adopters believed that they were too old to learn a new skill, which is the use of the Internet. Further, literature has found that the level of education is an added reason that affects ICT adoption and creates a digital divide [43]. This applies to both the developed countries and developing countries. A study conducted to examine the diffusion of ICT across the European Union (EU) found that university degree holding individuals are 5.1 times as likely to use the Internet compared to individuals with primary school education [44]. This was also confirmed in the context of Saudi Arabia where people with higher education attainment levels had increased tendencies to use technology than those who had lower levels of education [21]. This is similar to the findings of this study where the level of education had a vital role with regards to Internet adoption in older adults. It was found that the higher the education levels, the more the likelihood of Internet adoption, and vice versa. For example, the holders of higher and $1^{\text {st }}$ degrees were adopters at $100 \%$ and $93.9 \%$ respectively. Comparatively, the level of adoption was as low as $2.9 \%$ within participants who had no degrees or certificates qualifications (refer to table 1).

Further, older adults adoption research has found that socio-economic variables such as, gender and age have a considerable impact on the older adults' Internet adoption [3]. These variables also proved to be of significance in the technology acceptance research. Results exhibited that older adults age ranges are not identical when considering adoption within older adults (ibid). In light of this, this study has also found that age and gender do influence the adoption of the Internet. For instance, as mentioned earlier, younger older adults who are 50-59 of age are much more likely to be adopters than those who are over 70 years old: the adoption levels were at 97.2\% and $38.7 \%$ respectively. With regards to gender, this study found that the numbers of males' adopters are noticeably higher than females' adopters, which is something that stated in the research method section. That is, due to the cultural and social norms, the role of the male is prevalent in the Saudi Arabian community. This is why the level of male adopters was at $80 \%$ and the level of females adopters at $65.3 \%$ (refer to table 1).

To conclude, many studies of the Middle East found that age, gender and education are major causes of digital divides. For instance, in Turkey [45] age, and gender were important factors, but in Qatar, education was emphasized [46]; age, gender and education were emphasized in Jordan [6]; age and education in Saudi Arabia [21], [7]; and age in Oman [19]. The findings of this study were in line with the findings of the previous studies where there is a clear indication of the existence of age-based, gender-based and educationbased digital divides. Therefore, government should make more investments in ICT in terms of physical and social aspects [45]. Promoting and providing computer education programs to people, especially to older adults, is also important in bridging the digital divide [47].

\subsection{E-Government Services}

In terms of e-Government services, the quality of services in online government websites is a key aspect when considering the adoption and acceptance of such services within citizens [48]. Furthermore, a research conducted in Saudi Arabia found that citizens would consider e-Government services as quality services only when these services meet their needs [18]. In terms of this study, quality aspects of online services were included in the constructs of perceived website assistance (PWA), complexity (COMP), and perceived cyber risk (PCR). Further, PCR did not display a significant association with use intentions. However, PWA and COMP depicted strong correlations with the older adults' intentions to use the MOI e-portal. PWA and COMP correlated with the intentions to use by 0.163 , and 0.185 respectively.

Further, a critical factor that may affect the adoption of e-Gov services is trustworthiness. In a Middle East study of e-government, there was a positive association between the trustworthiness of e-Gov services and citizens belief. In turn, this has a significant effect on the intention to use the services [13]. Similarly, in the context of a major online-data breach, a recent USA study investigated the shopping intentions of older ( $>55$ years) and younger adults $(<55$ years) $[13]$ It 
was learnt that the trust of e-commerce and perceived online risk were negatively and considerably influenced after the incident of the large-scale breach. Interestingly, perceived risk has a greater impact on the older adults' online shopping intentions compared to the younger adults (ibid). Further, with respect to this current study, the findings also suggest a strong relation between the perceived risk (PR) and older adult's intention to use the MOI e-portal, which was shown by the resulting coefficient of 0.086 . Comparatively, although this study could not establish a strong connection between the trust of government (TOG) and intentions to use e-Gov, there is a strong relation between TOG and PR (coefficient of 0.120 ), which in turn influences the older adults intentions to use e-Gov. In light of these results, the government and official policy makers should promote trust and provide trustworthy services in citizens to encourage greater level of online services adoption [6]. Transparency by the government should also be promoted by informing citizens of the planned risk mitigation procedures in order to increase trust and minimize perceived risks [13].

Additionally, other Gulf region researchers have identified social influence to be of significance when considering the impact of the adoption of e-Gov services [20]. However, the outcome of the current research does not confirm such statements as the relation between social influence and older adults' intention to use e-Government services was not clearly evident. To confirm, or disprove such statements, in the next phase of this project, a larger sample sized population will be sought, which should lead to different outcomes. Further, trust of the Internet (TOI) was also identified in e-commerce adoption research as an important factor with regards to the adoption of e-Gov services [14]. Similarly, this study has also established a robust relation between TOI and older adults' intentions to use e-Gov services with the resulting coefficient of 0.226 , which suggests a large influence of TOI on intentions to use e-Gov services.

An additional factor that was studied by many researchers and depicted a crucial correlation with eGov services adoption is compatibility (COM) [12]. Compatibility in the context of e-Gov adoption refers to the degree that certain online government services align with citizens' daily work and personal lives. A study conducted in the context of Saudi Arabia to discuss the challenges facing e-government adoption found compatibility to be an encouraging aspect for citizens to adopt and use e-Gov services [21]. In this pilot study, results also showed a strong impact of COM on older adults' intentions to use e-Gov services as the resulting coefficient was 0.203.
Finally, in light of the findings of this research, for government to promote the use and adoption of its electronic services within the older adults citizens, there should be more efforts made to tackle the rising concerns of its older adults citizens. For instance, the government could launch a national campaign to publicize its online services provisions along with training sessions for the elderly [19]. Complexity of the portal is also an issue that needs to be addressed by the government. Results found that the simpler an online government portal is, the larger the intentions of the older citizens to use it [49].

\subsection{Implications of this Study}

For academia, the implication is that the results of this study will lead to a better understanding of the impacts of e-government services within a sociodemographic group of Saudi Arabia. That is, from our literature review, minimal studies of Saudi Arabia, more so, of e-government and older adults were available. Thus, our study should assist in providing more knowledge and awareness of e-Gov services in Saudi Arabia. For industry, this study identifies factors that private sector providers could use when providing particular goods and services within the Saudi Arabian community. For policymakers, this study attempts to identify ways that the e-government portal can become more pronounced within older citizens, which can also be the case within the younger citizens.

\section{Conclusions, Limitations and Future Directions}

This study aimed to identify, explain and understand the adoption and use of e-Government services within the older adults of a vicinity in Saudi Arabia. For this, a thriving vicinity of Saudi Arabia, Hail City was selected where a quantitative study that utilized hard and soft copies of questionnaires for data collection. It was found that age-based, gender-based and educationbased digital divides do exist in Saudi Arabia. Further, low quality online services generate lower uses of the services within citizens. To increase service use within citizens, government support in the form of raised awareness of internet use is suggested as this can assist in reducing the online risks within citizens. Further, this study examined a particular vicinity due to the vast distances to be covered that resulted in a few resulting outliers (e.g. factor loading of IM4). To overcome this, a suggested future direction is to seek a larger sample size and some rephrasing of questions. An added benefit is that with a much larger sample population, generalisations about the digital divide and e- 
government may be drawn. For this study, a quantitative approach was utilized. It is recommended that for the future, a qualitative approach involving interviews and/or observations will lead to a diverse perspective and an in-depth understanding of the older adults' needs and views towards e-Gov adoption. It is also recommended that a future research study could examine the regional differences that might exist within Saudi Arabia with respect to older adults and e-Gov adoption.

\section{References}

[1] N. C. Helbig, J. R. Gil-García, and E. Ferro, "Understanding the Complexity in Electronic Government: Implications from the Digital Divide literature", Proceedings of the Eleventh Americas Conference on Information systems, Omaha, NE, USA, August 11 th- $14^{\text {th }}$ (2005).

[2] C. Antonelli, "The digital divide: understanding the economics of new information and communication technology in the global economy", Information Economics and Policy, (2003), 15, pp. 173-199.

[3] B. Niehaves and R. Plattfaut, "Internet adoption by the elderly: employing IS technology acceptance theories for understanding the age-related digital divide", European Journal of Information Systems, (2014), 23(6): pp. 708726.

[4] World Health Organisation, "Health statistics and information systems: Definition of an older or elderly person", (2015), [Online] Available from

$<$ http://www.who.int/healthinfo/survey/ageingdefnolder/en/ $>$. [Accessed 2 Jun. 2015]

[5] Netlingo, "Silver surfer", (2013), [Online] Available from<http://www.netlingo.com/word/silversurfer.php\#sthas h.LCl68Iil.dpuf $>$ [Accessed 2 Jun. 2015].

[6] O. Alhujran, "Determinants of e-government services adoption in developing countries: a field survey and a case study", Doctor of Philosophy thesis. University of Wollongong Thesis Collection, (2009).

[7] F. Al-Sobhi, "The Roles of Intermediaries in the Adoption of E-Government Services in Saudi Arabia", (2011). [online] Available from $<$ http://core.kmi.open.ac.uk/download/pdf/6113215.pdf $>$

[Accessed 10th Dec. 2014].

[8] P. T. Jaeger and K. M. Thompson, "E-government around the world: Lessons, challenges, and future directions", Government Information Quarterly, (2003), 20. pp. 389-394.

[9] D. H. Brown and S. Thompson, "Priorities, policies and practice of e-government in a developing country context:
ICT infrastructure and diffusion in Jamaica", European Journal of Information Systems, (2011), 20, pp. 329-342.

[10] J. I. Criado and M. C. Ramilo, "E-Government in practice: an analysis of Web site orientation to the citizens in Spanish municipalities", The International Journal of Public Sector Management, (2003), 16(3). pp. 191-218.

[11] A. Phippen, "Evaluating Citizen Attitudes towards Local E-Government and a Comparison of Engagement methods in the UK", International Journal of Cases on Electronic Commerce, (2007), 3(3), pp. 55-71.

[12] L. Carter and F. Bélanger, "The utilization of egovernment services: citizen trust, innovation and acceptance factors". Information Systems Journal, (2005), 15: pp. 5-25.

[13] R. Chakraborty, J. Lee, S. Bagchi-Sen, S. Upadhyaya and H. Raghav Rao, "Online shopping intention in the context of data breach in online retail stores: An examination of older and younger adults", (2016), Decision Support Systems, 83, pp. 47-56.

[14] D. Kim, D. Ferrin and R. Rao, "A trust-based consumer decision-making model in electronic commerce: The role of trust, perceived risk, and their antecedents", Decision Support Systems, (2008), 44(2), pp. 544-564.

[15] T. Heart and E. Kalderon, "Older adults: Are they ready to adopt health-related ICT?", International journal of medical informatics, (2013), 8(2), pp. e209-e231.

[16] Stanford Center Longevity, "Critical Demographics of the Greater Middle East: A New Lens for Understanding Regional Issues", Global Aging Program, (2009).

[17] B. B. Neves, and F. Amaro, "Too old for technology? How the elderly of Lisbon use and perceive ICT", The Journal of Community Informatics, (2012). 8(1).

[18] M.A. Alanezi, A.K. Mahmood and, S. Basir, "Egovernment service quality: A qualitative evaluation in the case of Saudi Arabia”, EJISDC, (2012), 54(3), pp. 1-20.

[19] H. AlShihi, "Critical Factors in the Adoption and Diffusion of E-government Initiatives in Oman", Doctoral dissertation, Victoria University, Australia, (2006).

[20] S. AlAwadhi and A. Morris, "The use of the utaut model in the adoption of e-government services in Kuwait", Proceedings of the 41st Annual Hawaii International Conference on System Sciences, (2008).

[21] S. Alateyah, R. Crowder and G. Wills, “An Exploratory study of proposed factors to Adopt e-government Services: Saudi Arabia as a case study", International Journal of Advanced Computer Science and Applications, (2013), 4(11), pp. 57-66. 
[22] I. Lorge, "Irrevelant rewards in animal learning", Journal of Comparative Psychology. (1936), 21(1), pp. 105-128.

[23] Hovland, C., L. Janice and H. Kelley, Communication and Persuasion. Yale University Press, New Haven, CT.SPE: (1953).

[24] Fishbein, M. and I. Ajzen, Belief, Attitude, Intention and Behavior: An Introduction to Theory and Research, (1975).

[25] Feist, G. and E. Rosenberg, Psychology: Making Connections. McGraw-Hill, (2010).

[26] F. Bélanger and L. Carter, "Trust and risk in egovernment adoption", Journal of Strategic Information Systems. (2008), 17, pp.165-176.

[27] L.B. Rotter, "Generalized expectations for interpersonal trust". American Psychologist, (1971), 26 (5), pp. 443-452.

[28] I. Ajzen and M. Fishbein, "Attitudes and normative beliefs as factors influencing intentions". Journal of Personality and Social Psychology. (1972), 21 (1), pp. 1-9.

[29] Rogers, E., Diffusion of Innovations. The Free Press, New York, USA, (1995).

[30] L. Tornatzky and K. Klein, "Innovation characteristics and innovation adoption implementation: a meta- analysis of findings", IEEE Transactions on Engineering Management, (1982), 29, pp. 28-45.

[31] G. Moore and I. Benbasat, "Development of an instrument to measure the perceptions of adopting an information technology innovation". Information Systems Research, (1991), 2, pp. 173-191.

[32] V. Venkatesh and M. Morris, "Why don't men stop to ask for directions? Gender, social influence, and their role in technology acceptance and usage behaviour", MIS Quarterly, (2000a), 24(1), pp. 115-139.

[33] J. Wang, R. Chen, T. Herath and H. Rao, "Visual email authentication and identification services: an investigation of the effects on e-mail use", Decision Support Systems, (2009), 48(1), pp. 92-102.

[34] R. Chen and S.K. Sharma, "Learning and selfdisclosure behavior on social networking sites: the case of Facebook users", European Journal of Information Systems, (2015), 24, pp. 93-106

[35] M. Warkentin, D. Gefen, P. Pavlou and G. Rose, "Encouraging citizen adoption of e-government by building trust”, Electronic Markets, (2002), 12 (3), pp. 157-162.
[36] D. McKnight, V. Choudhury and C. Kacmar, "Developing and validating trust measures for e-commerce: an integrative approach", Information Systems Research, (2002), 13 (3), PP. 334-359.

[37] G. A. Johanson and G. P. Brooks, "Initial Scale Development: Sample Size for Pilot Studies", Educational and Psychological Measurement, (2010), 70(3), pp. 394-400.

[38] Saudi Central Department for Statistics \& Information. Population Estimates, (2010), Retrieved from http://www.cdsi.gov.sa/2010-07-31-07-00-05/cat_view/31/138----/342---1431-2010/300---.

[39] Litwin, M.S., How to Measure Survey Reliabilty And Validity, SAGE Publications, (1995).

[40] J. Henseler, C. M. Ringle and R. Sinkovics, "The use of partial least squares path modeling in international marketing”, Advances in International Marketing, (2009), 20, pp. 277-319.

[41] J. F. Hair, C. M. Ringle and M. Sarstedt, "PLS-SEM: Indeed a Silver Bullet", The Journal of Marketing Theory and Practice, (2011), 19(2), pp. 139-152.

[42] V. Venkatesh, M. Morris, G. Davis and F. Davis, "User acceptance of information technology: toward a unified view", (2003), MIS Quarterly, 27, pp. 425-478.

[43] Warschauer, M., Technology and Social Inclusion: Rethinking the Digital Divide. The MIT Press, (2004).

[44] M. R. Vicente and A. J. Lopez, "Patterns of ICT diffusion across the European Union", Economics Letters, (2006), 93(1), pp. 45-51.

[45] A. Acilar, "Exploring the aspects of digital divide in a developing country". Issues in Informing Science and Information Technology, (2011), 8, pp. 231-244.

[46] S. Al-Shafi and V. Weerakkody, "Factors affecting egovernment adoption in the state of Qatar". Proceedings of the European and Mediterranean Conference on Information Systems, (2010).

[47] Reffat, R., "Developing a Successful E-Government", (Working Paper): University Of Sydney, Australia, (2003).

[48] V. Kumar, B. Mukerji, I. Butt and A. Persaud, "Factors for Successful E-government Adoption: a Conceptual Framework", Electronic Journal of e-Government, (2007), 5(1), pp. 63-76.

[49] Al-Shehry, A. M., "Transformation towards egovernment in The Kingdom of Saudi Arabia: technological and organisational perspectives", A Doctoral Thesis, De Montfort University. UK, (2008). 